\title{
Analysing the Situation of ESL Teaching and Learning in Large University Classes in Pakistan
}

\author{
Abdul Hameed Panhwar ${ }^{1}$, Shah Nawaz Barich ${ }^{1} \&$ Syed Khuram Shahzad ${ }^{1}$ \\ ${ }^{1}$ Institute of English Language and Literature University of Sindh, Jamshoro, Pakistan \\ Correspondence: Abdul Hameed Panhwar, Institute of English Language and Literature University of Sindh, \\ Jamshoro, Pakistan. E-mail: hameed.panhwar@usindh.edu.pk
}

\author{
Received: May 5, $2020 \quad$ Accepted: July 7, $2020 \quad$ Online Published: July 30, 2020 \\ doi:10.5539/ijel.v10n5p250 URL: https://doi.org/10.5539/ijel.v10n5p250
}

\begin{abstract}
The present study is based on a chapter of the $\mathrm{PhD}$ project conducted by the main researcher. It aims to explore the ESL teaching and learning practices in a Pakistani university by focusing on difficulties perceived and confronted by learners and teachers, and solutions suggested by them. One of the most significant issues at the university is large classes-exceeding to 100 and more students on average. The main researcher, being an ESL teacher at the target university, faced the same problem of large size and found it difficult to teach these classes. He embarked on analysing the situation so that he might come across some solutions through the suggestions and experiences of the ESL teachers and students of the same university. The design of the study is descriptive and the results of the present study come from the quantitative data collected through student and teacher questionnaires. The Student-participants were 300 undergraduate students from various major subjects attending English language support classes and 22 ESL teachers teaching these English language support classes at different institutes of the university. The data were analysed descriptively and presented with help of the boxplots. The views, commonly held by teachers are supported by the study's findings i.e., large classes are likely to endorse teacher-centred approaches of teaching; very little significant student-student and teacher-student interaction is practised because of the inadequate physical environment; majority of learners remain off-task and appear to be unruly and they are given little, if any, feedback on their in-class and home tasks. Conversely, many teachers and learners reported that the adoption of group/pair work is likely to be an effective technique to use in these classes. Albeit a few teachers revealed having adopted group work infrequently, none used it all the time.
\end{abstract}

Keywords: ESL, teaching, learning, large classes, perceptions, experiences

\section{Introduction}

The present research paper analyses the situation of teaching-learning processes in large ESL classes in a Pakistani university where the main researcher (the first author) is working as an associate professor. The aim of the study is to have a clear picture of the situations and teacher-learners' practices. Also, based on teachers' and learners' informed suggestions, it aims at offering some solution to the problems, if any, encountered by the ESL learners and teachers in the target university due to a large number of students in their classes. However, the researchers experienced that ESL teaching in the university is difficult due to the size of classes and ineffective due to the traditional teaching methods used by the teachers (Rind \& Kadiwal, 2016).

The main author's own fourteen year teaching experience and personal observation at the target university and two studies (Bughio, 2013; Panhwar, Sangi, \& Zaib, 2018) conducted in the similar context led him to the idea that although for the learners these ESL classes are compulsory to attend, several of them are not found improving their English language proficiency, and thus, they linger to face problems in interacting in English. Hence, building on the ideas and findings of Nunan (1987), Nunan and Lamb (1996), Savignon (2002) and Ur (2004), it is hypothesised that this lack of improvement in the learners' English language proficiency is not because of the size of these classes, but it is argued that it is due to the use of the teacher-oriented instructive approach i.e., lecture-style teaching. According to Rind and Kadiwal (2016), this teacher-oriented method creates difficulties for learners to completely participate with the course content. Therefore, more communicative approaches to the teaching and learning of English as a second language are required in these large classes in Pakistan (Rind, 2015; Rind \& Kadiwal, 2016). However, the use of communicative language teaching is not that 
straightforward (Coskun, 2011). Many research studies suggest that before embarking on the use of communicative language teaching approaches in such difficult circumstances, firstly, one requires conducting need or situational analysis in order to better understand the situation and needs of teachers and learners (Shamim, 1993; Panhwar, 2016; Panhwar, Baloch, \& Khan, 2017a)

The literature on Communicative Language Teaching suggests that there is always the need of an exhaustive exploration of the educational context as part of the development of any curriculum (Richards, 1990; West, 1994; Savignon, 1991). Therefore, pedagogical innovations, based on socio-cultural approach, are always advocated (Savignon, 1991; Panhwar, Ansari, \& Ansari, 2016). Shamim (1993, p. 291) argues that “... innovations are organically developed after a realistic appraisal of the learning and teaching situation". Thus, in order to examine the validity of my personal context-oriented experiences and perceptions as a professor of English as a second language at a Pakistani university, the researchers' wanted to triangulate these both with other teachers' and their learners' experiences and perceptions in the similar context. Therefore, the situation was analysed in order to:

- gain a clearer picture of the methods and practices currently used by teachers in the ESL support classes at the target university;

- investigate the students' and teachers' perceptions and experiences;

- $\quad$ and take advantage of my colleagues' and their students' practical experiences, views and suggestions about how to make the situation more effective.

Following research questions were used:

1) What are students' and teachers' beliefs about and attitudes towards the significance of learning and teaching of English language in large classes at the target university?

2) What are students' and teachers' practices for and experiences of learning and teaching English language in their large classes at the university?

3) According to opinions of the teachers and students, how could their experiences and practices of ESL teaching and learning be improved?

With the first research question, the study aims to investigate the learners' and teachers' attitudes towards large classes. For example, how they feel and perceive about teaching and learning of English language in their large ESL classes. The second research question is used to explore what methods and techniques are used by the ESL teachers and learners, and how they practically cope with the situation. Hence responses to the first two research questions may be used to compare and check my own practices, experience and perceptions with those of colleagues. Finally, through the third research question, the researchers aim to explore what teachers and students, based on their experiences, suggest for the improvement of the scenario in these large ESL classes. This might help finding or formulating some pedagogical methods as solutions which may effectively be used in these ESL classes.

\section{Literature Review}

The available literature points out that a large number of teachers agree that large classes can be problematically difficult for teaching and learning of any subject, specifically English as a second language. The literature reviews the class size shows that various issues related to the large size of classes are faced by teachers and students in academic institutions of various countries. However, various studies (e.g., Kumar, 1992; Shamim, 1993; Bughio, 2013) have found these problems are argued to be serious in educational institutes of developing countries such as India, Pakistan, Thailand, China, and Nigeria. This section, based on the review of literature, aims to assess that according to teachers and learners, what a large class is, what problems are faced by them in large classes across the world and what ESL teachers and students suggest for making these classes more effective regarding the university teaching and learning.

\subsection{What Makes a Large Class?}

Perhaps, the Lancaster-Leeds Project, started at the University of Lancaster (1980s) by Dick Allwright, might be considered the most significant project on the class size impact on English language teaching and learning. The project surveyed teachers' perceptions to explore their perceptions about the class size. The results of the twelve reports of the project show a noticeable variation in the exact figure mentioned. This disparity was not only found between these reports, but within each report as well. LoCastro (1989) finds the highest discrepancy, where the number for a large class size extends from 9 to 100 students. A meta-analytical study of fourteen studies conducted by Todd (2006a) has found that the term 'large class' is relative and varies from a specific context to another. 
Coleman (1989) has found that the findings from 41 university and college lecturers from Jordan, Turkey and Indonesia reveal that the mean number of students given for an unpleasantly large class is 43 students. Therefore, on the whole, based on the results of the Lancaster-Leeds projects, the reported average size for a large class that becomes uncomfortable for teaching and learning of English Language is 40-45 learners (Coleman, 1989; Peachy, 1989; LoCastro, 1989).

\subsection{Teacher-Student Perceptions}

Regarding teachers' perceptions and experiences of teaching large ESL classes, Panhwar et al. (2018) report that majority of teachers find teaching large ESL classes difficult because of their large size and noise and disruption created by the large groups. Moreover, because these classes have an enormously large size, teachers find it difficult to use modern interactive teaching methods and feel compelled to use traditional lecturing. According to Todd (2006a), the factors arguably affecting the teachers' perceptions of the size of classes may cover the age of students; the subject teachers teach; the level of education and motivation of teachers and students, and the size of their classroom.

On the other hand, many research studies, for example, Shamim (1993), Hayes (1997), Shamim, Negash, Chuku and Demewoz (2007) and Panhwar et al. (2018) also investigated the perceptions of school ESL teachers of large classes and discovered similar findings. Shamim (1993, pp. 140-143) investigated Pakistani secondary school ESL teachers' beliefs of and attitudes towards teaching of English in large classes through interviews with 20 teachers. she found that " $\ldots$ their previous experience in classes of varying size, the average class size in the immediate educational context and the physical conditions in the classroom" influenced their beliefs and views of what makes a large class.

There is a much smaller number of research studies on learners' views on large ESL classes than those on teachers. At the university level, Bughio (2013) found that the major problem that learners perceived was the difference in the degree of participation in the class. Only a few brighter students with the fluent level of English dominated the class with their participation and the weaker and shyer students felt frightened and discouraged. This shows that insufficient participation of students in large ESL classes leads to demotivation. Shamim (1993) also found that Pakistani secondary school students were not comfortable in their large crowded classes; the situation of disorderliness and uproar produced by the enormous number of learners disturbed them. According to the learners, the teacher could not pay heed to them or establish interaction with them which created demotivation in them. Similarly, Bandiera, Larcinese and Rasul's (2010) findings also corroborate Shamim's (1993) results. Thus, regarding ESL classes, substantial similarity can be observed between the students' and teachers' perceptions at different levels and in different contexts.

Some research studies and projects on the perceptions of university learners in different disciplines have found similar results. For example, in a review study on learners' perceptions conducted by Mulryan-Kyne (2010) learners reported that large classes reduce student-student, teacher-student and student-teacher communication; therefore, learners remained anonymous and passive throughout their academic year/semester. Large size of classes negatively influenced student participation in the class and their involvement with the content of the syllabus was minimised. For example, Bandiera et al. (2010) by exploring the link between MSc learners' contentment and the number of students in their classes found that they were substantially less contented in their institutes which have on average larger size classes. Moreover, owing to the anonymous nature, large classes often encourage students to ignore the rules and their responsibilities, so they do not come in the class on time and mostly many uninterested students are found to leave early (Mulryan-Kyne, 2010; Bandiera et al., 2010).

Thus, overall findings of the literature on class size suggest that large classes are perceived both by teachers and learners as adverse and problematic, and both the teachers and students both in language teaching and content-teaching contexts at all levels extensively agree to the perceived problems across the world specifically in developing countries.

\subsection{Problems Experienced by Teachers and Learners}

The problems associated to large classes perceived and experienced both by teachers and learners can be summarized as: problem in remembering names of learners and creating rapport with them; extremely loud noise and deteriorated conditions of discipline; lack of classroom material and equipment; difficulty in assessing student work and providing feedback; little teacher attention given to students individually and the insufficient opportunities for learners to communicate and participate and for teachers to set up and monitor communicative activities. These all problems lead students to remain anonymous, passive and demotivated (McLeod, 1989; Coleman, 1989; LoCastro, 1989; Shamim, 1993; Bughio, 2012; Panhwar, 2016; Panhwar et al., 2018). 
Whatever teachers' beliefs of large ESL classes are, the majority of teachers in developing countries are found reporting that they always teach classes with the size which exceeds their perceived ideal size (Coleman, 1989; Shamim, 1993; Bughio, 2012; Panhwar, 2016; Panhwar et al., 2018). This underscores the phenomena that large sized classes are not commonly believed to be ideal. Most noticeably and importantly, teachers of large ESL classes report that in large classes they often cannot remember the learners' names and, consequently, it leads them to feel that they become unable to connect with their students in positive and trusting relationships.

LoCastro (1989) and McLeod (1989), the two of the major studies of the Lancaster-Leeds Project, found that many teachers reported that it was hard for them to learn students' names, to establish understanding relationship, to establish eye contact with all learners and to evaluate their interest. Another study conducted in Thailand by Jimakorn and Singhasiri (2006) found that a significant number of teacher-student participants thought that large ESL classes create difficult situations for teaching and learning of English language, and therefore less effective. Many teachers of universities in emerging countries like Pakistan, India and Thailand indicate that it becomes problematic for them in large ESL classes to establish a trusting and positive relationship with students (Kumar, 1992; Jimakorn \& Singhasiri, 2006; Bughio, 2013; Panhwar, 2016; Panhwar et al., 2018). Panhwar et al. (2018) found that the large ESL classes were disruptive and communicative strategies were not used frequently. Only a few more able students participated and interacted with teachers in these classes; most of students could not hear the teacher and see the black board; the majority of students were off-task; little feedback was given to students on their work by the teacher.

\subsection{Class Size Impact on Learners' Engagement and Attainment}

Effects of large classes are mostly negative as compared to their counterpart smaller classes. The studies like Todd (2006b), Bughio (2013) and Panhwar et al. (2018) have found little about positive side of large class size. Todd (2006b) conducted an analysis on the discourse of students and teachers during a class comprised of short lectures, teacher-oriented interaction, presentations and group work. Two ESL undergraduate classes (i.e. one small-23 students and the other larger - 41 students) were taught by the similar teacher based on the same lesson plan at a university of Technology, Thailand. The study's results, on the whole, found no substantial impact of the size of a class on teaching with one exception that the teacher called individual learners by name in the smaller class more frequently. There was no significant disparity in the teacher-oriented questions, feedback by the teacher, repetition or rephrasing of questions by the teacher and in the teacher-talk time. However, this study may be deemed limited because it was based on only one class, therefore, its findings may not be generalised. Also, the large class was below the size at which classes especially ESL/TESOL classes are generally considered to be problematically uncomfortable and large i.e., 43-44 students.

Another study, Bughio (2013) while comparing the interview results of the university teachers and students with the results of class observations of the large ESL classes discovered that the study findings largely confirmed the teacher-student beliefs and perceptions of large classes presented in the review of the literature. The study reveals that there was a noticeable difference in the large ESL classes at the target university regarding language competence, and student participation. Only few stronger front bench students participated and answered the teacher-oriented questions. While other students in the middle and at the back of the class remained silent and off-task most of time. The teachers interviewed for the study blamed the size of class for the lack of student participation and engagement with the learning process in the class.

However, Bughio (2013) himself concludes these problems were mostly the result of the ineffective instructional techniques used by the target university teachers, not completely the result of the class size. This study shows a clear discrepancy in the findings. In the class observation, teachers' teaching practices did not confirm what they actually reported in their interviews. For instance, although some teachers claimed in their interview reports that they tried to use interactive activities and involve all the learners in their classes, the results from the classroom observation show that they made very little efforts to use communicative techniques and engage students. Bughio (2013) argues that this scenario actually indicated that teachers were not trained to teach large ESL classes. The majority of the teachers, interviewed and observed, possessed MA degree in English Literature and were untrained to teach these classes.

Another observation study i.e., Harfitt (2012) conducted classroom observation of ESL classes of three school teachers in a secondary school, Hong Kong. In the study the number of learners in large classes was at least 40 and smaller classes were of less than 40 students. The results of the study reveal that there was a clear substantial disparity in teacher-oriented interaction with students owing to the size of the class. Smaller classes provided more chances to the teacher to change their questions and their types and to communicate more enormously with their students. However, some studies Kumar (1992), Blatchford, Bassett and Brown (2005), Mulryan-Kyne (2010), 
Harfitt (2012), Bughio (2013) and Panhwar (2016) appear to reveal that it may be possible both to improve the effectiveness of small classes and to decrease the ineffectiveness of large classes by selecting right pedagogical approaches that may maximise chances for student participation, enhance learner autonomy and diminish the dependence of students on direct interaction with teachers. Hence, based on the results obtained through the literature review, the present research paper would make an attempt to investigate whether these results may or may not be corroborated.

\subsection{Large Classes and Group Work}

The ESL/TESOL literature reveals that group work may diminish the negative impact of large classes regarding students' learning. For example, it is argued by Hess (2001) and Wharton and Race (1999) that the use of group/pair activities may be an effective way to help learners practise English language in their large classes, and can create many opportunities for learners to become autonomous and develop independent learning skills. According to Nolasco and Arthur (1988), group and pair work makes students to work simultaneously which maximises the practice time of learning the target language, and also because of interactive nature of group/work activities students are less likely to be overtaken by boredom and lack of interest. In summary, with the adoption of group/pair tasks, learners come at the centre of learning, and the teacher facilitates learners with an atmosphere that enables students to work collaboratively and smoothly.

In terms of content teaching-learning processes in higher education, there is a substantial body of research on the adoption of a more structured approach to group work, namely cooperative learning (cf. Cooper \& Robinson, 2002; Smith, 2000). For instance, Smith (2000) and Cooper and Robinson (2002), through analyses of the research studies on cooperative learning and personal association with the teachers in colleges and universities, found that, generally, the adoption of cooperative learning activities helps students progress in their critical thinking because these activities of cooperative learning make students engage in arguments and reasoning. Moreover, these activities develop the social bond by assisting learners to get to know one another and let go of differences. The strategies of cooperative learning also offer quick feedback to learners, first from their classmates and then from their teachers.

\section{Methodology}

\subsection{Data Collection}

The study uses quantitative approach. The instruments used were teacher and student questionnaires. The study uses questionnaires to collect a large quantity of generalisable data (Cohen, Manion, \& Morrison, 2007) in a lesser duration of time and at much smaller budget than other methods like interviews (Cohen et al., 2007). The use of survey instruments enabled the researchers to maintain greater confidentiality and anonymity as well. Participants' anonymity is ensured with the use of the questionnaire because, unlike in an interview, they do not come face-to-face with the researchers. Moreover, the questionnaires used in the current study did not ask participants to state sensitive information like their names or classes (cf. Strange, Forest, Oakley, \& Ripple, 2003; Cohen et al., 2007). Conversely, survey protocols too carry numerous limitations, such as the risk of gathering erroneous data and inadequate chances for the investigator to have a trusting understanding with respondents (Jekayinfa, 2007; Harris \& Brown, 2010). To recompense for the given shortcomings, the researchers made every possible effort to be in contact with the respondents during and after the completion of these survey forms as recommended by Cohen et al. (2007).

\subsection{Data Analysis}

The questionnaires of the study were comprised of Likert scale items (strongly agree to strongly disagree) which elicited ordinal data. The data were analysed through SPSS and is graphically presented with the help of box and whisker plots. Butler (1985) argues that when the design of the study is descriptive, data are ordinal, and they are not normal in distribution, then the median could be the most appropriate unit of central tendency and the inter-quartile range (IQR) could be the best measure of distribution. Therefore, based on the argument put forward by Butler (1985), the median was considered to show the central tendency in the current study's data, and IQR to reveal the spread. Moreover, since box plots display the central tendency and spread of data in pictorial form, they are taken as an effective method of quickly matching several sets of information (Jones, 1997; Bakker, Rolf, \& Cliff, 2004) such as the answers to each of the items on the questionnaires used in the present study (Pallant, 2005).

\subsection{Participants of the Study}

22 ESL teachers and 208 second-year undergraduate students at the target university were the participants of the study. Student-participants were studying in compulsory language support classes. The second-year undergraduate students were sampled because of their before-hand ESL learning experience in the language 
classes at the target university and consequently could share more reliable and conversant views and experience than the first-year undergraduates. Compulsory ESL classes are not offered to the students of Third and fourth year. Therefore, asking for their views and experiences would not have been direct and therefore less straightforward.

\subsection{Sampling}

The purposive stratified random sampling was adopted to have a representative observations and opinions. Firstly, three faculties i.e., the Faculty of Natural Sciences, Social Sciences and Arts were chosen. The Faculty of Natural Sciences and Social Sciences were sampled because are the target university's largest faculties. The main researcher chose the Faculty of Arts because he himself is employed in that faculty. The three largest departments (one from each faculty) were selected: The Institute of English Language and Literature from Arts; the Department of Zoology from Natural Sciences and the Department of Sociology from Social Sciences (see Table 1).

Table 1. Faculties and the number of students enrolled

\begin{tabular}{lll}
\hline Faculty & No. of institutes/departments & Total no. of students enrolled \\
\hline Natural Sciences & 22 & 7852 \\
Social Sciences & 17 & 4467 \\
Arts & 7 & 1400 \\
\hline
\end{tabular}

\subsection{Instruments}

The data were collected through following a student questionnaire and a teacher questionnaire. Two adapted questionnaires (Thaher, 2004; Jimakorn \& Singhasiri, 2006) (one for teachers and other for students) were used to gather quantitative data. Table 2 below lists the instruments and their details.

Table 2. Instruments and participants for data collection

\begin{tabular}{ll}
\hline Data collection instruments & Number of Participants \\
\hline Teacher-questionnaire & 22 ESL teachers \\
Student-questionnaire & 300 2nd year undergraduate students of compulsory ESL classes \\
\hline
\end{tabular}

Data from student-participants

The selected classes were visited by the main researcher with permission of the teacher concerned and asked the students present in the class to complete the questionnaire. The main researcher remained in the class until the questionnaires were completed and returned. 208 student-questionnaires were returned and included in the study. The mean age of the student-participants who returned the completed instruments was twenty years, with range values 17-26. There were 114 (55\%) male students and 94 (45\%) were female students.

Data from teacher-participants

All the available 22 ESL teachers at the target university completed and returned the copies of the teacher-questionnaire which were later processed for analysis. Among these teachers, male teachers were 15 $(68 \%)$, and female teachers were $7(32 \%)$ in number. Table 3 below lists the details of these ESL teachers.

Table 3. Sampled Teachers for the study

\begin{tabular}{ll}
\hline Experience of teaching & Number of teachers \\
\hline 1-year teaching experience & two \\
1 to 5-year teaching experience & eight \\
6 to 10-year teaching experience & eight \\
11 to 15-year teaching experience & one \\
16-year and more teaching experience & three \\
Total & Twenty-two \\
\hline
\end{tabular}

\section{Findings and Discussion}

The statements on the questionnaires produced Likert-scale quantitative data that are represented pictorially 
through box and whisker plots. The following three main areas are covered by the data of the study:

$>$ Teacher-student perceptions about class size;

$>$ Teacher-student perceptions about teaching and learning in large ESL classes;

$>$ Teacher-student experiences of teaching and learning in these classes.

\subsection{Experienced and Perceived Class Sizes}

Following three questions about class sizes were asked from the teacher and student participants on their questionnaires:

$>$ What is their usual class size?

$>$ At what number of students does the size of a class start to create problems for them?

$>$ What is the ideal number of students for a class to have, in their opinion?

The first question asks about the size of their ESL classes which the teachers teach and students learn in usually. The second question inquires of their views on the size of class which makes it difficult and less effective for them to teach and learn. The third question attempts to obtain the information about the size of the class which was perceived by them (teachers and students) to be the ideal size and it might make the teaching and learning of English as a second language more comfortable and more communicative for them. Table 4 shows the findings elicited by these questions.

Table 4. Student-teacher experiences and perceptions of class size

\begin{tabular}{llll}
\hline Participants & Usual class size (Average size) & Problematically large size (Average size) & Ideal size (Average size) \\
\hline Teachers' responses & 104 & 69 & 38 \\
Students' response & 134 & 102 & 58 \\
\hline
\end{tabular}

Based on the findings represented by Table 4, for all of three sizes, the teacher-participants have reported lesser numbers on average. The size they usually teach ESL classes i.e., 104 students is a far larger size than the size i.e. 69 students they believe to be problematically large, and the size i.e., 38 students they reported to be an ideal size to teach ESL classes effectively. Conversely, the findings suggest that the learners generally learn in larger classes that is classes with 134 students on average than the size of the classes they recognize to be problematically large i.e., 102 student-class, where their study of English language becomes demanding for them. The average ideal size reported by the student participants i.e., 58 students is much larger than what the teachers perceive as an ideal size for them to teach and far smaller than the class size they (students) usually learn in. Thus, the results indicate that learners rarely practise learning in their ideal size ESL classes.

Hence, generally, the findings reveal that both the learners and teachers encounter the classes they consider to be problematically enormous in number, and much larger than the size they reported for an ideal class. The results gained from the teachers and students clearly corroborate that the concept of 'large class' is relative as stated in the literature. The relatively large sizes reported mirror the fact that the respondents experience very large ESL classes. However, surprisingly the mean number specified by the teacher-participants in the present study for an ideal size of a class falls just below the number of about 40 students which other studies in the literature suggest makes the ESL teaching difficult and ineffective.

\subsection{Teacher-Learner Perceptions of Teaching and Learning in Large ESL Classes}

A 5 -point Likert scale $(1=$ strongly disagree, $2=$ disagree, $3=$ uncertain, $4=$ agree, and $5=$ strongly agree $)$ in the teacher-student questionnaire is used to draw their perceptions and experience of the teaching and learning of English language in large classes. The teacher-student respondents were to opt for a series of statements selecting one scale of their choice.

The analysed data are presented descriptively and box and whisker plots are used to graphically display the results. The central part of the box plot (the box-shape also called IQR) carries $50 \%$ of the values. The dark strip in the box (IQR) stands for the median. The straight lines at both the sides of the box are called the whiskers which embody the general range of values and the asterisk and dots around the whiskers represent outliers.

In the graphs of box plots used for the display of the findings, each box plot presents the array of replies to a specific statement on the adopted questionnaires. Three colours (Green, Red and Citron) can be seen in the box plots. The statements representing the box plot with Red colour show negative responses from the respondents 
about teaching and learning in large ESL classes. Positive responses are represented by the statements (box plots) of Green colour. The statement showing the box plots with Citron colour show that responses were insignificant with no clear consensus. Green and Red colours in the boxes of box plots show that the statements exhibit substantial consensus to either 'agree' or 'disagree'. This means when a box (IQR) is of Red colour, the responses connected to the statement show that the majority of the participants disagree with the statement and when a box (IQR) is of Green colour, the responses connected to the statement reveal that a significantly substantial number of the participants agrees with the statement.

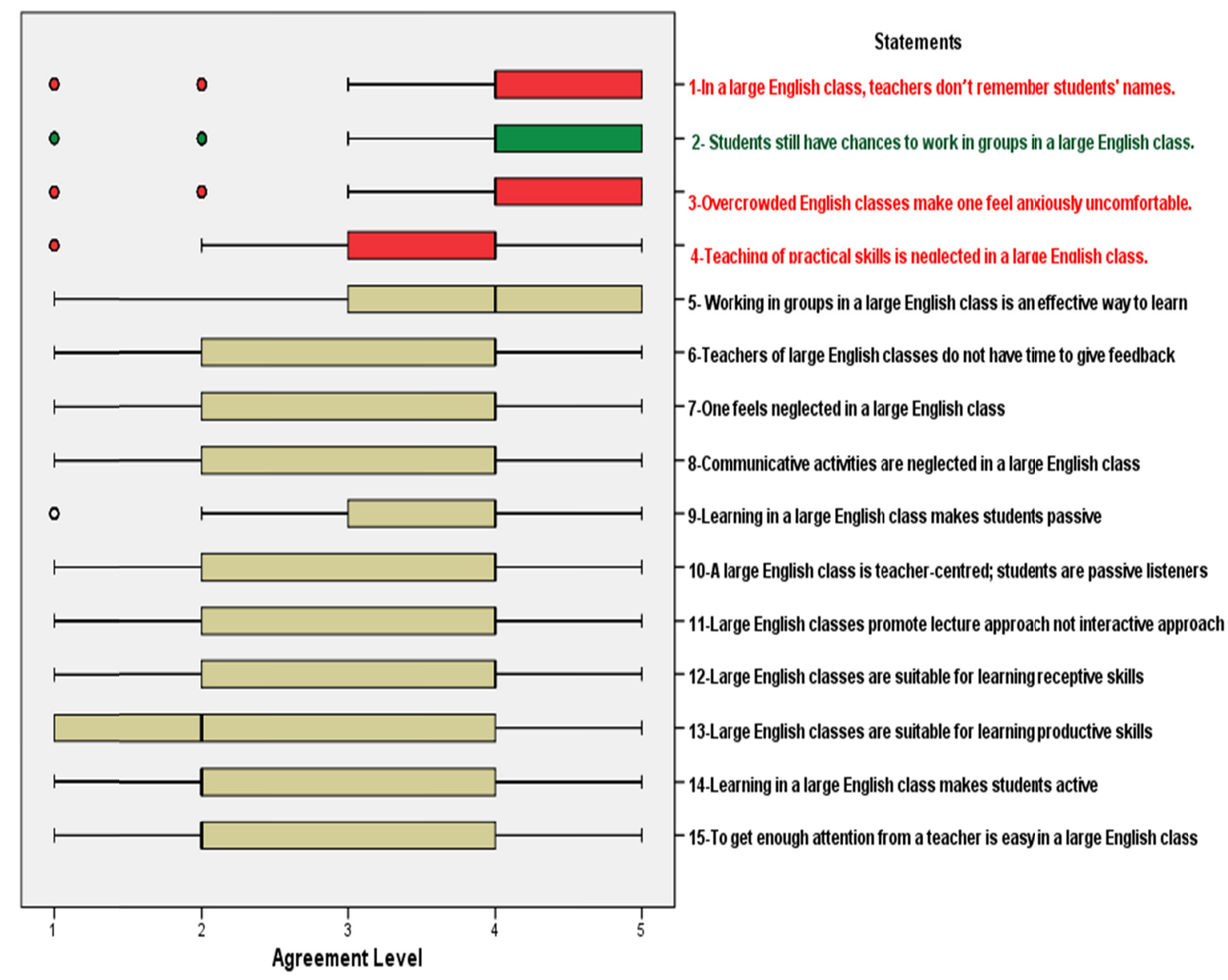

Figure 1. Perceptions of learners regarding learning in large ESL classes $(\mathrm{N}=208)$

Learner-participants' perceptions

Responses to 15 statements by the student participants are represented by Figure 1 about the possible benefits and flaws of ESL learning in large classes. It is noticeably clear that out of 15 statements, only 5 statements produce considerable consensus. The statements from 1 to 3 show the maximum degree of agreement and the statements 4 and 5 demonstrate a slightly reduced agreement, but these are still conspicuous in consensus. The responses to the statements 1,3 and 4 reveal that a substantial number of the learner-respondents believed that large ESL classes have negative impact on the learning of English language. The majority of them have perceptions that their teachers do not recall their names, they feel uncomfortable in large ESL classes and the teaching through practical and interactive methods is often ignored by their teachers in these classes.

However, to the statements 2 and 4 the responses of the student-participants show that a great number of students consider that the use of group activities may conceivably make English language teaching and learning operative and effective in large ESL classes. The remaining statements' responses by the students reveal an extensive variety of views and perceptions. Therefore, their findings may not be safely generalised. It is probably 
surprising to find such a variety of views given by the student-participants which are not completely consistent with the findings of the literature about the difficulties and problems linked with large ESL classes. However, the student-participants clearly agree that these problematically large classes create discomfort for them; teachers do not recall their names, and practical communicative language methods are not used.

Looking at the positive side of large ESL classes, it is really motivating to observe that the majority of the learners in the study believe that the adoption of group/pair work is likely to be an advantageous method for large ESL classes. This finding contradicts Shamim's (1993) finding which is that the secondary school learners in Pakistan did not like studying English language through group work. There may be numerous likely reasons for this dissimilarity. First of all, the participants in Shamim's (1993) study were secondary school learners, but the students in the current study are adult university undergraduates. Therefore, perhaps, younger pupils are more reliant on the teacher-oriented pedagogical methods than adult learners who are more capable of seeing the paybacks of working autonomously in groups. The other reason may be that two and half decades have passed since Shamim (1993) was conducted. This time pass might have changed Pakistani learners' traditional attitudes towards ESL learning and teaching. Lastly, the student behaviour to group work might have begun to change as a consequence of the study conducted in the same university by Bughio (2013).

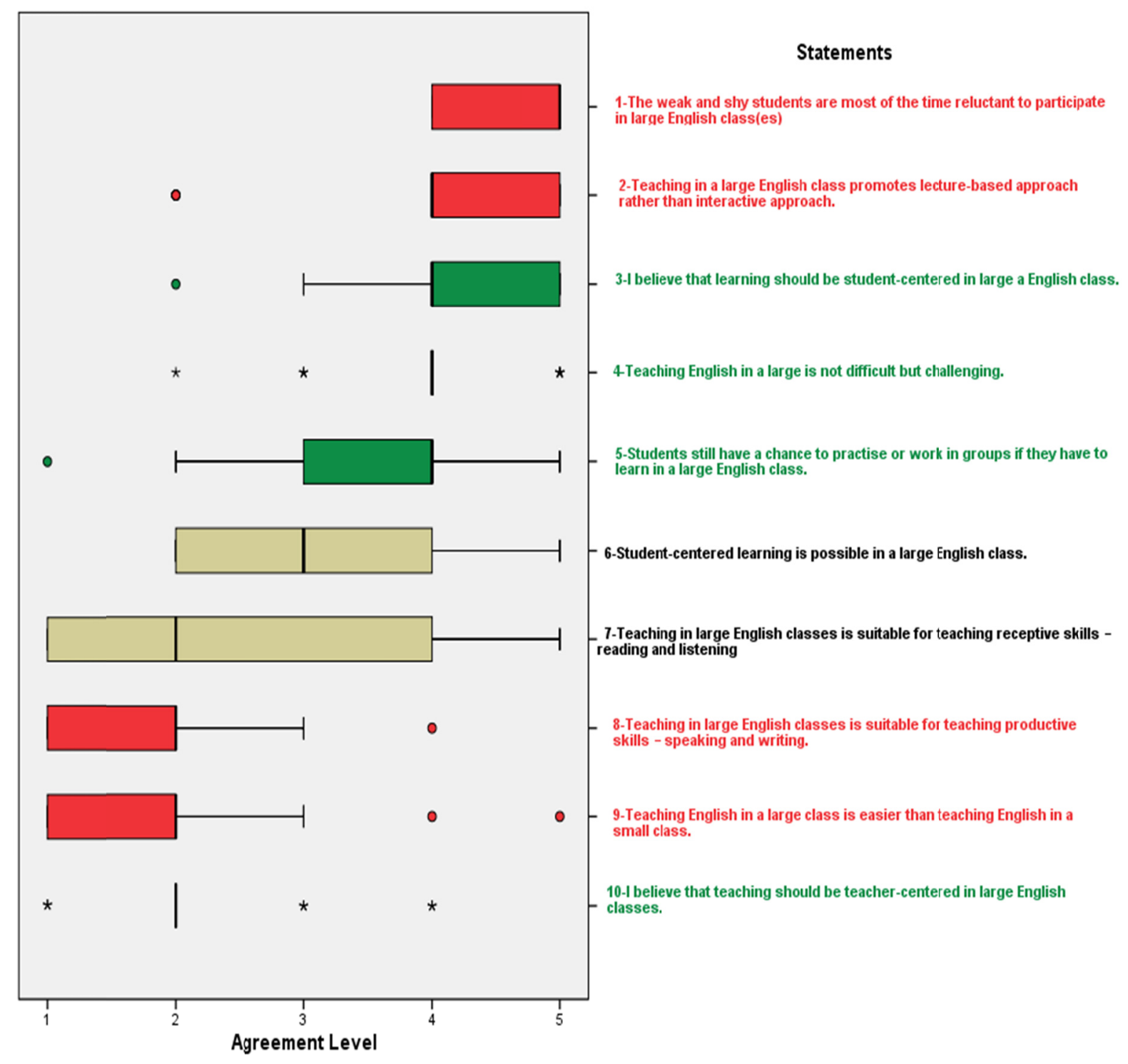

Figure 2. Teachers' perceptions of teaching English language in large ESL classes $(\mathrm{N}=22)$ 


\section{Teacher-participants' perceptions}

In comparison to the student-participants' responses, the teacher-participants' responses display a far larger degree of agreement with one another (see Figure 2). In Figure 2, the statement 9 shows that nearly no teachers perceived that teaching English language in large size ESL classes was easier than teaching English language in small ESL classes. However, in the responses to the statement 4, virtually all the teacher-participants agreed that teaching large ESL classes was not difficult but rather a challenging job which is a positive behaviour to the situation.

The statements 3 and 10 show that approximately all the teachers believe that ESL teaching and learning should be learner-oriented not teacher-oriented. Nevertheless, the responses to the statement 6 show a substantial discrepancy or ambiguity about if this may be practicable in large ESL classes. Almost all the teachers notice that large ESL classes encourage a lecture-style method and collaborative teaching and learning methods are not very possible (see the responses to statement 2). Similarly, the responses to the statements 7 and 8 reflect the same belief. For example, the students substantially believed that large ESL classes are unsuitable to teach and learn productive skills. However, there is no clear consensus about if these classes are even appropriate for teaching and learning of receptive skills. On the whole, the findings mirror that there is the robust agreement amongst the learners that, in large ESL classes, the teachers neglect to teach practical skills through the communicative teaching approach.

The statement 1 shows the greatest agreement among the teachers. Almost all the teachers who participated in the survey perceive that overcrowded ESL classes, with an enormous number of learners, generate unwillingness in the weak and shy learners to participate in the class activities. Thus, again, it is reflected by the learners' perceptions that large congested ESL classes create anxiety amongst them. The statement 5 shows that many teachers do not believe that group work can effectively address this problem of ineffectiveness. On the whole, these findings suggest that there is a clash of perceptions among the teachers. For example, on the one hand, they believe that large ESL classes should be taught through student-centred learning; on the other hand, they reflect it to be essentially not possible in these very large language classes.

\subsection{Learner-Teacher Experiences of Learning and Teaching in Large ESL Classes}

In the preceding section, the views of the learners and lecturers about large ESL classes were dealt. In this part, the real learner-teacher practices in and experiences of the large ESL classes at the target university are shown. The student-teacher participants were invited to rate a chain of statements linked to their experiences on 5-point scale $(1=$ strongly disagree to $5=$ strongly agree $)$ as before. 


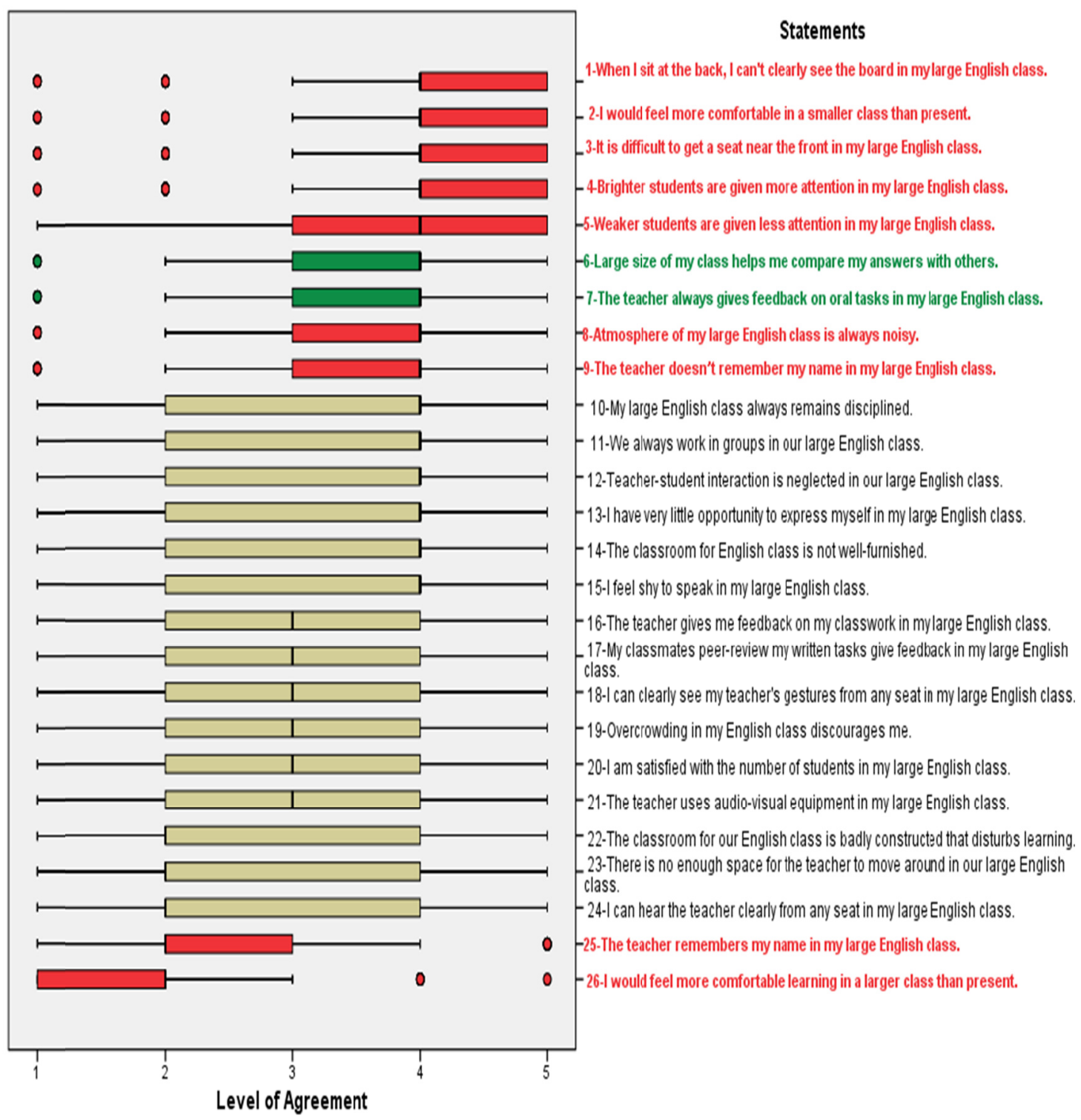

Figure 3. Learners' experiences of learning in large ESL classes $(\mathrm{N}=208)$

\section{Learner-participants' experiences}

Through Figure 3, the responses of the learner-participants to 26 statements are displayed. As compared to learners' perceptions given above, in the responses related to the learners' experiences, there is substantial disagreement or vagueness about the numerous issues associated with class size. However, the responses to statements 1 to 9 and statements 25 and 26 show strong consensus. In the responses to the statements 2 and 26 , the learners show consensus that the smaller classes would make them more comfortable. According to the responses to the statement 3 , the learners have difficulty to get the seat in the front rows in their current large ESL classes because when they sit in the back rows, they are not able to see the black board (see the statement 1). The responses to the statement 8 indicate that the learners' large ESL classes are continuously noisy and disturbing, and the responses to the statement 9 and 25 show that the learners' teachers do not often recall their names. Furthermore, according to the students' experiences, the teachers give most of the attention to the brightest students (see the statements 4 and 5). However, on the positive side, the learners substantially agree that the large number of students in these classes becomes helpful for them to compare their written tasks with others' (see the statement 6).

These findings openly corroborate the results of Shamim (1993) who found that the classroom's physical 
structure has a main role in defining the learners' ability for participation in large ESL classes. Similarly, Bughio (2013) found that the teacher mostly directed his/her attention towards the academically more active students in these classes. In the light of the findings of Shamim (1993) and Bughio (2013), it is surprising for the present study to find that in the responses to the statement 7, a substantial number of the students agree that they are always given feedback by their teachers on their spoken tasks. Conversely, it is worth-mentioning here that according to Bughio (2013), spoken tasks in these ESL classes were usually comprised of student presentations mostly given by few brighter students regularly.

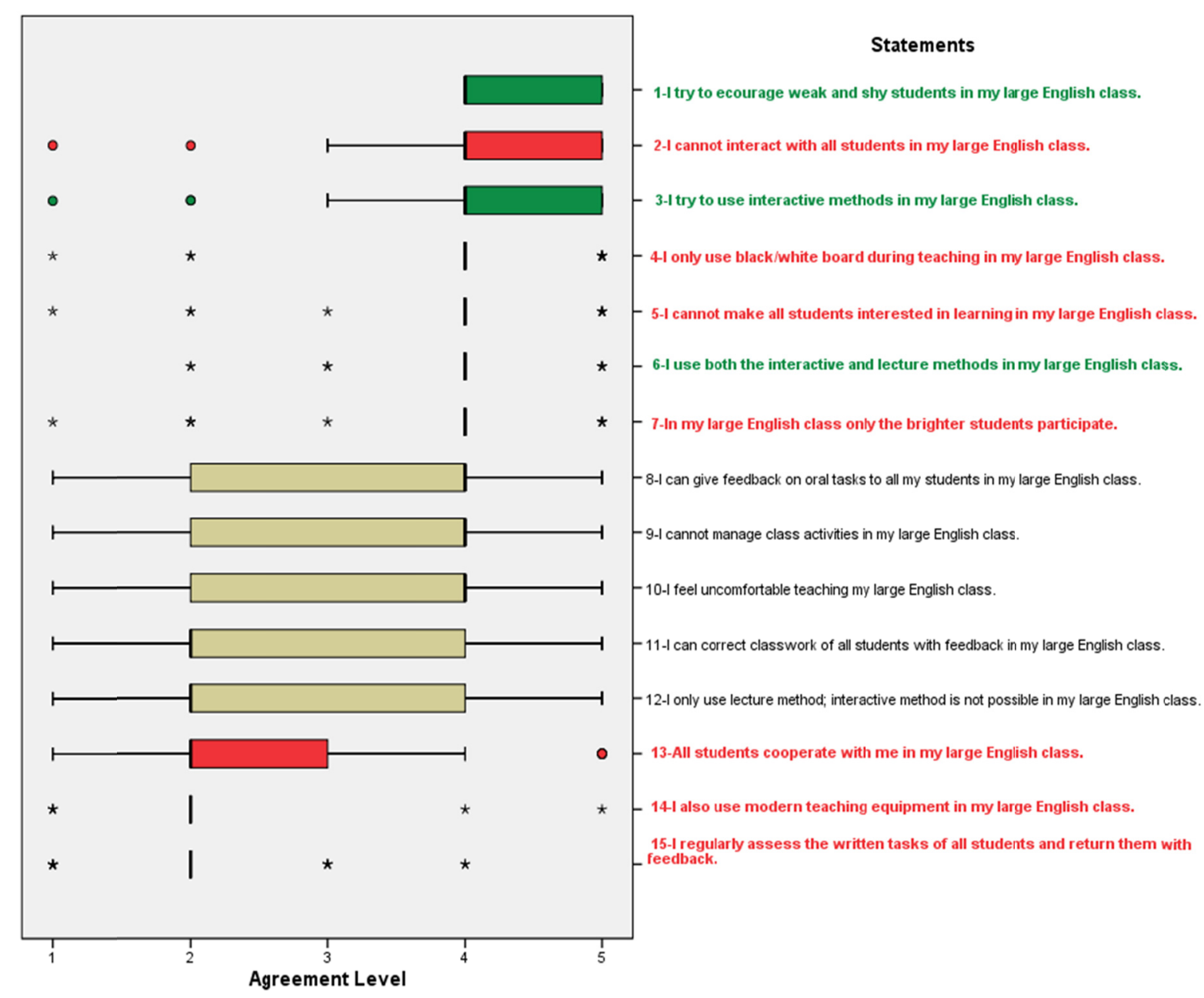

Figure 4. Teacher-participants experiences of teaching in large ESL classes $(\mathrm{N}=208)$

\section{Teacher-participants' experiences}

In Figure 4 the responses of the teacher-participants to 15 statements about their teaching practices and experiences in large ESL classes are illustrated. Once again, the findings from the responses show the tension between what the teacher-participants would like to do but they cannot do, and what they find possible and they do. On the one hand, in accordance to the responses indicated by the statements 3, 6 and 1 respectively, nearly all the teachers responded that they make attempts to adopt some communicative teaching methods alongside lecturing, and to hearten the weak and shy learners for participation in the class activities. On the other hand, they (teachers) agree that they are not able to interact with all the learners (see the statement 2) and they find it difficult to make all the learners take interest in learning language practically (see the statement 5). According to the responses to the statements 13 and 7 respectively, all the learners are not cooperative, and only the strongest students participate. The responses to the statements 14 and 4 show that the teachers at the target university do not have up-to-date teaching equipment to use in their classrooms; consequently, they only utilise black/whiteboards. Moreover, the teachers face difficulty in assessing and giving feedback on the learners' 
written in-class or home assignments.

To conclude, generally, the responses of the learners and teachers substantiate each other. The only observed inconsistency is between the statement 7 on the learners' graph and the statement 8 on the teachers' graph. For instance, although the learners respond that the feedback on their spoken tasks is frequently given by their teachers, the teachers are not completely certain about this. Save for this one divergence, the opinions of the teachers endorse those of the learners. All the learners and teachers accept that the physical surroundings in the classrooms are not helpful for learning. The instructors do not have any audio-visual aids; therefore, it becomes very difficult for the learners sitting at the backside of the classroom to see whatever the teachers write on the black/whiteboard. Moreover, there is solid understanding that only the more capable learners partake in the class activities. Hence, apparently the outcome is that the breach between the less bright and brighter students unyieldingly increases. Based on this situation, it appears glaringly evident that what is required is some framework that either keeps the similar learners from continually sitting nearest to the board or, even better; it moves the focus away from the board by and large.

\section{Conclusion}

From the results of the situational investigation exhibited in this paper, a definite and steady picture rises about the teaching and learning circumstances in the large ESL classes at the target university. This has been substantiated by analyses and findings of the quantitative data obtained from the teachers and students. The outcomes of the study confirm the view generally held by teachers about large ESL classes revealed in the literature. For example, teachers commonly believe and experience that these classes appear to encourage teacher-oriented approaches for teaching of English language (see Coleman, 1989, 1989b; LoCastro, 1989; McLeod, 1989; Jimakorn \& Singhasiri, 2006; Panhwar, 2016; Panhwar et al., 2018). Precisely, the situation indicates that in these ESL classes, the student participation and communication with the teacher is tremendously irregular and limited to a few more competent learners. This patchy interaction may be the consequence of the insufficient physical setting, because the learners sitting at the back are unable see what is written on the board and hear what the teacher speaks. Moreover, thus, because most of the learners are off-task in the lesson, they appear to be disruptive. Also, the teacher is able to give very little, if any, feedback on the learners' written tasks.

A considerable number of the teachers and learners perceived that group/pair work may be practised to teach and learn English language in these classes effectively. This outcome is considerably in line with the literature on class size (see Section Literature Review). However, the teachers did not use group work on a regular basis. According to both the teachers and learners, the main reason that hinders them from using group work and other interactive activities more often is the large size of their ESL classes. Specifically, according to the teachers the adoption of group work creates disorderly situation in the class and the creation of groups takes excessively much time.

Group work is most frequently reflected as the only method which may help give students the responsibility for their learning. It is seen that through the use of group work, learners can teach and learn from one another. Nonetheless, group work is a very general term, and it requires teachers to develop its strategies on their own (Cooper \& Robinson, 2002; Panhwar, 2016). Thus, it demands from them to spend a sizeable quantity of time in working out and testing these activities. Group work, as frequently specified by teachers, can be harmful to the class discipline, if it is not very cautiously structured and planned.

Hence, it is assumed that a more structured approach to group work is needed which may assist teachers to save time and use group strategies more smoothly, with previously set-up techniques and activities and rules for learners to follow. Numerous research studies (see Johnson \& Johnson, 1974; Cooper \& Robinson, 2002; Panhwar, Gopang, Chachar, \& Baloch, 2017b), reviewed in the current study, recommend the adoption of cooperative learning because it is a more organised form of group work. The adoption of cooperative learning permits teachers to sidestep the difficulties during formulating group strategies, wasting time on the creation of groups and classroom indiscipline. Hypothetically, if these difficulties are the chief hindrances which prevent teachers from adopting more collaborative methods in their ESL classes, then as hypothesised cooperative learning is argued to empower them to do so.

\section{References}

Allwright, D. (1989). How important are lessons anyway (p. 12)? [pdf] Lancaster: Lancaster-Leeds Language Learning in Large Classes Research Project.

Blatchford, P., Bassett, P., \& Brown, P. (2005). Teachers' and pupils' behaviour in large and small classes: A systematic observation study of pupils aged 10/11 years. Journal of Educational Psychology, 97(3), 
454-467. https://doi.org/10.1037/0022-0663.97.3.454

British Council. (2015). English Language in Pakistan's Higher Education. Research Report. Retrieved from https://www.britishcouncil.pk

Bughio, F. A. (2013). Improving English language teaching in large classes at university level in Pakistan. Doctoral dissertation, University of Sussex. Retrieved from http://sro.sussex.ac.uk/id/eprint/45170/

Coleman, H. (1989). How large are large classes? [pdf] Lancaster: Lancaster-Leeds Language Learning in Large Classes Research Project, Report 04. Retrieved from http://eric.ed.gov/?id=ED322759

Cooper, J. L., \& Robinson, P. (2002). The argument for making large classes seem small. New Directions for Teaching and Learning, 81, 5-16. https://doi.org/10.1002/t1.8101

Harfitt, G. J., \& Tsui, A. B. (2015). An examination of class size reduction on teaching and learning processes: A theoretical perspective. British Educational Research Journal, 41(5), 845-865. https://doi.org/10.1002/berj.3165

Jimakorn, P., \& Singhasiri, W. (2006). Teachers' beliefs concerning large-class English teaching at the university level. rEFLections. KMUTT Journal of Language Education (Special issue: Large Classes), 9, 13-23. Retrieved from http://arts.kmutt.ac.th/sola/rEFL/Vol9_Reflections_Large

Johnson, D. W., \& Johnson, R. T. (1974). Instructional goal structure: Cooperative, competitive, or individualistic. Review of Educational Research, 44(2), 213-240. https://doi.org/10.3102/00346543044002213

Kumar, K. (1992). Does class size really make a difference? - Exploring classroom interaction in large and small classes. RELC Journal, 23(1), 29-47. https://doi.org/10.1177/003368829202300103

LoCastro, V. (1989). Large size classes: The situation in Japan. [pdf] Lancaster: Lancaster-Leeds Language Learning in Large Classes Research Project, Report 05. Retrieved from http://eric.ed.gov/?id=ED322758

McLeod, N. (1989). What teachers cannot do in large classes? [pdf] Lancaster: Lancaster-Leeds Language Learning in Large Classes Research Project. Report No. 7. Overseas Education Unit, School of Education, University of Leeds, Leeds LS2 9JT, United Kingdom.

Nunan, D. (1987). Communicative language teaching: Making it work. ELT Journal, 41(2), 136-145. https://doi.org/10.1093/elt/41.2.136

Nunan, D., \& Lamb, C. (1996). The self-directed teacher. Cambridge: Cambridge University Press.

Panhwar, A. H. (2016). Using cooperative learning to enhance student engagement with language support classes in Pakistani higher education. Doctoral dissertation, Anglia Ruskin University, Cambridge, UK.

Panhwar, A. H., Ansari, S., \& Ansari, K. (2016). Sociocultural theory and its role in the development of language pedagogy. Advances in Language and Literary Studies, 7(6), 183-188. https://doi.org/10.7575/aiac.alls.v.7n.6p.183

Panhwar, A. H., Baloch, S., \& Khan, S. (2017a). Making communicative language teaching work in Pakistan. International Journal of English Linguistics, 7(3), 226-234. https://doi.org/10.5539/ijel.v7n3p226

Panhwar, A. H., Gopang, A. S., Chachar, Z. A., \& Baloch, S. (2017b). Differentiating Cooperative Learning and Collaborative Learning: What Is Fit for Pakistani Higher Education? International Journal of English Linguistics, 7(5), 119-126. https://doi.org/10.5539/ijel.v7n5p119

Panhwar, A. H., Sangi, M. K., \& Zaib, S. (2018). Teacher-Student Perceptions and Experience of Large ESL Classes at The University of Sindh, Jamshoro Pakistan. International Journal of Management and Applied Science, 4(11).

Peachey, L. (1989). Language learning in large classes: A pilot study of South African data. Lancaster: Lancaster-Leeds Language Learning in Large Classes Research Project Report No. 8. Overseas Education Unit, School of Education, University of Leeds, Leeds LS2 9JT, United Kingdom.

Renaud, S., Tannenbaum, E., \& Stantial, P. (2007). Student-centred teaching in large classes with limited resources. English Teaching Forum Online, 3, 12-17. Retrieved from http://americanenglish.state.gov/files/ae/resource_pdf.

Richards, J. C. (1990). The Language Teaching Matrix. Cambridge: Cambridge University Press. https://doi.org/10.1017/CBO9780511667152 
Richards, J. C. (2006). Communicative language teaching today. New York: Cambridge University Press.

Savignon, S. J. (2002). Communicative language teaching: Linguistic theory and classroom practice. In S. J. Savignon (Ed.), Interpreting communicative language teaching: Contexts and concerns in teacher education (pp. 1-27). London and New Haven: Yale University Press.

Shamin, F. (1993). Teacher-learner behaviour and classroom processes in large ESL classes in Pakistan. Doctoral dissertation, University of Leeds.

Shamin, F. (2011). English as the language for development in Pakistan: Issues, challenges and possible solutions. In H. Coleman (Ed.), Dreams and Realities: Developing Countries and the English Langauge. London: British Council.

Shamim, F., Negash, N., Chuku, C., \& Demewoz, N. (2007). Maximizing learning in large classes: Issues and options. [pdf] Addis Ababa: British Council.

Strange, V., Forest, S., Oakley, A., \& Ripple. (2003). Using research questionnaires with young people in schools: The influence of the social context. International Journal of Social Research Methodology, 6(4), 337-346. https://doi.org/10.1080/1364557021000024749

Todd, R. W. (2006). Why investigate large classes. Journal of Language Education (Special issue: Large Classes), 9, 1-12. Retrieved from http://arts.kmutt.ac.th/sola/rEFL/Vol9_Reflections_Large_Classes.pdf

Todd, R. W. (2012). The effects of class size on English learning at a Thai university. ELT Research Journal, 1(1), 80-88. https://doi.org/10.5539/elt.v6n11p49

West, R. (1994). Needs analysis in language teaching. Language Teaching, 27(01), 1-19. https://doi.org/10.1017/S0261444800007527

\section{Copyrights}

Copyright for this article is retained by the author, with first publication rights granted to the journal.

This is an open-access article distributed under the terms and conditions of the Creative Commons Attribution license (http://creativecommons.org/licenses/by/4.0/). 